\title{
Student nurse perception of doctoral graduate programs
}

\author{
Peggy Ward-Smith, Jane Anthony Peterson, Susan Kimble \\ School of Nursing and Health Studies, University of Missouri, Kansas City, United States.
}

Correspondence: Peggy Ward-Smith. Address: School of Nursing and Health Studies, University of Missouri, Kansas City, United States. Email: wardsmithp@umkc.edu

Received: January 7, 2014

DOI : $10.5430 /$ jnep.v4n5p36
Accepted: February 7, $2014 \quad$ Online Published: March 4, 2014

URL: http://dx.doi.org/10.5430/jnep.v4n5p36

\section{Abstract}

Purpose: The purpose of this study was to explore the perception of nursing students, enrolled in either a DNP or PhD program, of the roles and responsibilities of nurses with terminal degrees. Using the items identified by position statements from the AACN, a study-specific Likert-response survey was developed.

Data sources: Data were collected from 199 students, presently enrolled in either a DNP or PhD program. Survey Monkey ${ }^{\circledR}$ was used to collect these data. Study consent was implied upon submission of the survey responses. Descriptive statistics were used to describe the roles/responsibilities of each degree.

Finding / Results: Discriminating the role/responsibility of the DNP and PhD-prepared nurse, with respect to research or clinical focus, was clear. Leadership, mentoring, and dissemination of knowledge activities were perceived to be a responsibility of the nurse educated with either degree. Policy activities, utilizing theory for research and/or practice, data analyses, and mentoring activities were not identified as critical to either role.

Implications: These data identify course content which should be included in each educational program. These results also describe areas in which additional focus is needed to clarify the roles/responsibilities of the DNP and PhD-prepared nurse.

\section{Key words}

Doctorate of nursing practice, Doctorate of philosophy in nursing, Student perception, Survey

\section{I ntroduction}

Nurses seeking advanced education and a terminal degree within the profession have two separate options, either a Doctorate of Nursing Practice (DNP) or a Doctorate of Philosophy in Nursing (PhD) ${ }^{[1]}$. Both degrees are perceived as a highest, or terminal, academic degree in nursing, yet each has a different outcome focus. Graduates of these degree programs provide different contributions to the nursing profession. The DNP and PhD educational programs share demanding requirements for successful completion. According to Chism ${ }^{[2]}$, the DNP degree prepares nurses at the highest level of clinical expertise with a commitment to a practice career. Nurses with a DNP degree are expected to contribute to healthcare improvement through clinical practice, application of research, and policy development. The PhD prepared nurse has a focus on nursing research with a commitment to improving healthcare through the development of new knowledge and scholarly endeavors that provide the foundation for the advancement of nursing science ${ }^{[1]}$. The purpose of 
this study was to explore the perceptions of nursing doctoral students (enrolled in DNP or PhD program coursework) regarding the roles and responsibilities associated with the two educational programs.

\subsection{Historical perspective of doctoral education in nursing}

According to Robb ${ }^{[3]}$, the first doctoral nursing program was established in 1920 at Teachers College and focused on preparing teachers of nursing with a Doctor of Education degree (EdD). New York University established the first Doctorate of Philosophy (PhD) in Nursing in 1934. In the early 1950's, the University of Pittsburgh recognized the importance of clinical research in advancing nursing knowledge and established a $\mathrm{PhD}$ in Maternal and Child Nursing. Boston University developed the Doctor of Nursing Science (DNSc) to focus on professional nursing practice in the 1950s. Several other universities offered variations of the DNSc, such as the Doctor of Nursing Science (DNS), and the Doctor of Nursing (ND). By the 1960s most nurses seeking a doctoral education obtained their degree in other scientific disciplines ${ }^{[3]}$. Four doctoral educational preparations for nurses were available after the 1960 s, including PhD in nursing, $\mathrm{PhD}$ in another discipline, (such as the psychology or the biological sciences), the DNSc or ND practice doctorate, and the educational doctorate (EdD). Contrary to what some people might think, a practice doctorate for nursing is not a new concept ${ }^{[4]}$. The doctor of nursing practice (ND) was first established by Case Western Reserve University in 1979; however Case Western and four other universities converted their ND programs to DNP programs in recent years ${ }^{[5]}$.

In $1986^{[6]}$, AACN first published the indicators for quality doctoral nursing education. The Indicators for Quality in Research-Focused Doctoral Programs in Nursing supported a single set of indicators for researched focused programs, whether the degree was a PhD or a DNS/DNSc. AACN revised the indicators in 2006 to outline the educational goals for each of the terminal doctoral programs in nursing. In 2006, the AACN published a Roadmap Taskforce report ${ }^{[1]}$. This report describes the key differences between the DNP and $\mathrm{PhD}$ education programs by delineating that the DNP-prepared nurse has a commitment to a practice career and the $\mathrm{PhD}$-prepared nurse as having a commitment to a research career.

In 2004, the DNP was recognized by AACN as a terminal practice degree to prepare nurses for a complex clinical practice environment ${ }^{[7]}$. The DNP prepares nurse specialists at the highest level of advanced practice (AACN). A DNP degree prepares nurses for a professional career that is designed for practice scholarship by improving patient care outcomes, policy development, advocacy, and healthcare systems management ${ }^{[5]}$. The $\mathrm{PhD}$ prepares the nurse scientist for a career in research scholarship with the goal of improving nursing practice and healthcare delivery ${ }^{[7]}$. Despite these seemingly clear descriptions and program outcomes, it seems that doctoral students remain unclear about the purposes and role preparations regarding the two nursing doctoral degrees. Therefore, this survey was conducted to determine the perceptions of PhD and DNP doctoral students regarding the roles of the DNP and PhD prepared nurse.

\subsection{Current trends in nursing doctoral education}

The Robert Woods Johnson Foundation Initiative on the Future of Nursing Report recommends that the number of doctoral-prepared nurses be doubled by 2020 for leadership roles in meeting the healthcare needs of the nation ${ }^{[8]}$. The IOM recognizes the DNP as the terminal degree in nursing to improve healthcare. The increasing numbers of nurses seeking DNP education may be represented by AACN's response to changes in health care delivery, emerging healthcare needs, IOM's report on the Future of Nursing, and "the recognition that nurses need to advance their education and develop the skills needed to thrive in contemporary care settings" ${ }^{[9]}$. Although there has been a recommendation to increase the number of doctoral-prepared nurses, the specific doctoral degree and the nurses' role are not clearly delineated in this report.

AACN currently has 222 member schools offering a DNP program and 127 member schools with a PhD program. Enrollment is increasing in both the DNP and PhD programs in the U.S. however DNP enrollment is increasing at a higher rate ${ }^{[10]}$. There are approximately 54\% more students enrolled in a DNP program than the PhD programs, yet there has also been an increase in enrollment in the PhD programs by $52 \%$ since $2003^{[11]}$. As of January 2103 , AACN reported there are more than 100 additional nursing schools nationwide considering starting a DNP program ${ }^{[9]}$. Approximately 4,907 nursing students were enrolled in research-focused doctoral programs (PhD), and 9,094 nursing students were enrolled in practice-focused doctoral programs (DNP) in nursing in $2012^{[9]}$. There is concern that with the rapid growth in DNP 
programs and the current overall faculty shortage, implementation DNP curricula will occur at the cost of other nursing educational programs, specifically the $\mathrm{PhD}$ prepared research doctorate ${ }^{[12]}$.

Prior to the IOM's ${ }^{[8]}$ recommendation to increase the number of doctoral prepared nurses, Loomis and associates ${ }^{[13]}$ conducted an online survey of DNP students $(n=69)$ to determine what factors influenced their decision to choose the DNP program versus a $\mathrm{PhD}$ program. Findings suggest that 55\% of respondents had considered the PhD degree option prior to choosing the DNP. Primary factors that deterred the DNP student from choosing a PhD program was the perceived longer length of time required to attain a PhD than DNP, the lack of availability of the $\mathrm{PhD}$ online, and the DNP was thought to be more compatible with their career goals ${ }^{[13]}$. Among these DNP students, their most common career goal was to work in nursing education (55\%); 39.1\% were interested in clinical practice. Interestingly, the goal of DNP education is not to prepare nurse educators, but to prepare nurses at the highest level of clinical practice preparation ${ }^{[5]}$. Although there is minimal literature to support this hypothesis, it seems nurses choosing doctoral programs are unclear regarding the purposes and role preparations of the two nursing doctoral degrees. Therefore, this online survey was conducted to determine the perceptions of $\mathrm{PhD}$ and $\mathrm{DNP}$ doctoral students regarding the roles of the $\mathrm{DNP}$ and $\mathrm{PhD}$ prepared nurse.

Choosing an academic program and especially choosing between two doctoral nursing degrees can be particularly daunting for the prospective graduate student ${ }^{[14]}$. Unfortunately, there continues to be some confusion concerning the two doctoral nursing degrees, which may be exacerbated by the various levels of preparation for nurses, nurse practitioners, and/or advanced practice nurses ${ }^{[12]}$. The potential graduate student may be confused by the varied and confusing nomenclature used by universities in the description of the two degrees ${ }^{[15]}$. Additionally, there are a number of other degree options when considering a doctoral program, including an $\mathrm{EdD}$, a $\mathrm{PhD}$ in another discipline, or a practice specific doctorate, such as the doctor of nurse anesthesia (DNAP). The future role that the potential graduate student seeks should be strongly considered, however if the long term goal of the prospective student is to become nursing faculty, neither doctoral degree typically prepares the student for a faculty role ${ }^{[16]}$. Determining the potential students' perceptions of the two doctoral degrees will help inform admissions personnel and doctoral-program faculty to provide appropriate materials and counseling to assist the student in selection of the educational tract that best meets their personal and professional goals.

\section{Method}

\subsection{The survey study}

Institutional Review Board (IRB) approval from the employer of the researchers is a required University policy prior to initiating any study activity. The IRB determined that this study was minimal risk study and consent could be assumed upon submission of the survey responses. Invitations to participate in this study were emailed to the Dean of Schools of Nursing, identified by the AACN as providing both the DNP and the $\mathrm{PhD}(\mathrm{N}=78)$ degree options. Deans were asked to share this research opportunity with faculty who teach didactic course work within DNP/PhD educational tracks and to forward to the invitation and survey link to their students. To maintain participant anonymity, there was an inability to send reminder emails to the Nursing Deans.

The study-specific instrument was developed; each item reflected the content of the 22 AACN-identified doctoral indicators ${ }^{[1]}$. Responses to each survey item were dichotomous, which allowed each participant to identify the perceived educational preparation (DNP, PhD, both) for the skill identified in the item. The ability to skip, or non-respond, to any item was provided. IRB guidelines and FERPA mandates limited the amount of demographic information that could be obtained. Thus, minimal demographic data were collected, limiting the ability to describe the study population.

\subsection{Data collection}

Each invitational email included the web-based link to the study survey. If participation was desired, accessing the link provided directions describing the study aim, purpose, and time required for participation. The study site remained open 
for three months, which allowed for any variation in semester starts and stops to not impede study participation. The participation rate cannot be determined because the exact number of potential study participants is unknown. Blenner's ${ }^{\text {[17] }}$ rule of at least five subjects per item was used to guide data collection. Sufficient responses were obtained, eliminating the need to request IRB approval for follow-up letters.

\section{Results}

One hundred ninety-nine complete responses were received. Demographically, study participants self-described themselves as between the ages of 20-30 years $(n=41 ; 21 \%), 30-41$ years $(n=54 ; 27 \%), 41-50$ years $(n=54 ; 27 \%), 51-60$ years $(n=47 ; 24 \%)$, with $3(1 \%)$ individuals reporting an age of 60 years or older. Of the participants who self-disclosed their educational track 68 (35\%) were enrolled in a Doctoral of Nursing Practice (DNP) track, 124 (65\%) were enrolled in a Doctorate of Philosophy (PhD) educational track; 7 participants did not identify an educational track. The majority of these participants $(n=117 ; 58.8 \%)$ reported not being licensed as an advanced practice nurse (APN) at the present time.

Responses for each item were calculated. While there were no items which received a response in more than one category, there were 27 incidences of a lack of response to a specific item. Since there were 13,134 potential responses (22 items X 3 possible responses [66] and 199 participants [13,134]), this calculates to a $0.2 \%$ of missing data. According to Monroe (1997), this is acceptable, and these data may be considered reliable. No individual response set had greater than two missing datum, therefor all data sets were included in the analyses. All data were transferred into a study-specific SPSS file and triple-checked for accuracy prior to initiating analyses. Descriptive analyses procedures were used to answer the study purpose.

Discriminating the role and/or responsibility of the DNP or PhD prepared nurse, for some AACN indicators was clear. A DNP-prepared nurse, in the perception of these participants, was clearly focused on providing healthcare with a high level of clinical expertise. Roles for the PhD-prepared nurse included a commitment to a research career, conducting original research, and securing research funding. Confusing, or blending of the roles were apparent with respect to mentoring other nurses, leadership positions in healthcare, in depth knowledge of a particular area, and communicating scholarship through publications and presentations. The similarity of the item which assessed mentoring new nurses and the item which assessed providing professional and research mentoring may have some crossover in the responses. The top five responses, based on educational preparation, are presented in Table 1. The top five, in descending order, roles perceived to be germane to the DNP prepared nurse are (1) a high level of clinical expertise, (2) providing healthcare, (3) designing evidence-based interventions, (4) improving healthcare delivery, and (5) identifying gaps in practice evidence. The top five, in descending order, of roles perceived to be a responsibility of the $\mathrm{PhD}$ prepared nurse are (1) a commitment to a research career, (2) conducting original research, (3) securing funding for research, (4) developing new knowledge, and (5) fulfilling faculty responsibilities. There are several indicators, identified by the AACN to be an indicator for quality doctoral nursing education (DNP or PhD), which, in the perspective of these participants, was not critical. These included (1) healthcare policy activities, (2) utilizing theory for research and/or practice, (3) analysis of practice data, (4) integrate research, teaching, mentoring and service, and (5) provide professional and research mentoring.

Table 1. The top five indicator responses

\begin{tabular}{lll}
\hline DNP Prepared Nurse & PhD Prepared Nurse & Both DNP and PhD Prepared Nurse \\
\hline High level of clinical expertise & Commitment to a research career & Mentoring other nurses \\
Provision of healthcare & Conduct original research & In depth knowledge of a particular area \\
Design evidence based interventions & Securing funding research & Leadership position in healthcare \\
Improve healthcare delivery & Development of new knowledge & Participate in interdisciplinary research \\
Identify gaps in evidence for practice & Fulfilling faculty responsibilities & Communicate scholarship through \\
& & publication and presentation \\
\hline
\end{tabular}

Note. Top five survey responses, by educational preparation 
Based on these responses, the roles and responsibilities of both DNP and PhD-prepared nurses are clearer than the roles and responsibilities of the DNP-prepared nurse. The mean scores of the top five (treating each tie as a single unit) for this category was 107.8 (SD, 3.77). The mean scores of the top five responses for the PhD-prepared nurse was 71.4 (SD, 25.48), with the mean scores for the top five DNP-prepared nurse was 40.0 (SD, 16.88). Fifty-five percent of the PhD students who completed the survey indicated that they were most interested in pursuing faculty roles or positions upon degree completion

\section{Discussion}

These responses indicate that when assessing the specific roles and responsibilities of each specific educational track, there are no overlapping indicator(s), between the educational preparations. This indicates that in the perception of these study participants, the roles and responsibilities for the DNP and PhD-prepared nurse overlap. Therefore, based on the doctoral students in this study, the role and responsibilities for the PhD-prepared nurse are clearly identified, while the role and responsibilities of the DNP-prepared nurse seem to be more ambiguously understood. However, since nearly twice as many respondents were PhD students, this over-representation may skew study findings.

Currently, a nursing faculty shortage does exist with approximately 1,181 faculty positions vacant in the U.S. ${ }^{[11]}$. Therefore it is essential to increase the number of qualified nursing faculty ${ }^{[18]}$. Studies have shown that factors leading to faculty shortage include low faculty salaries, increasing age and retirement of nurse faculty, nurses seeking doctoral degrees at mid-career or later, minimal preparation for faculty roles, heavier teaching, committee, and research demands within universities, and incivility among nursing faculty and students ${ }^{[19,20]}$. However, typically neither nursing doctoral degrees prepare graduates as nurse educators and doctoral program curricula typically do not include curriculum design and evaluation, educational outcomes assessment, advisement, accreditation procedures, skills in didactic or clinical teaching, or managing student incivility. Faculty in both DNP and PhD doctoral programs need to be incorporating educational opportunities to prepare doctoral students for future nurse faculty roles.

\section{Recommendations}

The pursuit of any educational program should align and support one's professional career goals. Knowledge with respect to the job functions of DNP and/or PhD-prepared nurses is important and impacts the ability to seek the appropriate degree. Student information which clearly defines and describes the educational requirements of both degrees, and the subsequent career opportunities, will provide information that can guide the decision-making process. This information should be included in student advising activities and curriculum development.

Nursing students seeking a terminal degree in nursing should be encouraged to identify career goals, whether it is more research or practice focus, as well as the desire for leadership, mentoring, faculty positions, conduction and utilization of research, improving healthcare policy and evaluation of healthcare. Providing the ability to complete several courses, required of both educational programs, before making a career decision, is a viable solution for institutions that provide both doctoral programs. Acknowledging that the nursing profession needs both doctoral-degree preparations and it is important to guide students toward the appropriate degree choice. For DNP and PhD students that are interested in the nurse educator role, strategies for preparing students for nurse faculty roles are essential. The inclusion of nursing education curriculum will provide a cost effective education while enhancing our profession.

\section{References}

[1] American Academy of Colleges of Nursing. Essentials of doctoral education for advanced nursing practice. 2006. Available from: http://www.aacn.nche.edu/ publications/position/DNPEssentials.pdf

[2] Chism, L.A. Toward clarification of the Doctor of Nursing Practice Degree. Advanced Emergency Nursing Journal. 2009; 31(4): 287-297. PMid:20118882 http://dx.doi.org/10.1097/TME.0b013e3181be0fd6 
[3] Robb. W.J. The ABCs of nursing doctoral degrees. Dimensions in Critical Care Nursing. 2005; 24(2): 89-96. http://dx.doi.org/10.1097/00003465-200503000-00010

[4] Hawkins, R., \& Nezat, G. Doctoral education: which degree to pursue? American Association of Nurse Anesthetists Journal. 2009; 77(2): 92-96.

[5] American Association of Colleges of Nursing. DNP fact sheet. 2013. Available from: http://www.aacn.nche.edu/ media-relations/fact-sheets/dnp

[6] American Association of Colleges of Nursing. Indicators of quality in research-focused doctoral programs in nursing. 2001. Available from: http://www.aacn.nche.edupublications/position/quality-indicators

[7] American Association of Colleges of Nursing. AACN position statement on the practice doctorate in nursing. 2004. Available from http://www.aacn.nche.edu/DNP/DNPPositionStatement.htm

[8] Institute of Medicine. The future of nursing: Leading change, advancing health. 2011. Washington, DC: National Academies Press.

[9] American Association of Colleges of Nursing. New AACN data show an enrollment surge in baccalaureate and graduate programs amid calls for more highly educated nurses. 2012. Available from: http://www.aacn.nche.edu/ news/articles/2012/enrollment-d

[10] American Association of Colleges of Nursing. The research-focused doctoral program in nursing: Pathways to excellence. n.d Available from: http://www.aacn.nche.edu/education-resources/phdposition.pdf

[11] American Association of Colleges of Nursing. Nursing Faculty Shortage. 2012. Available from: http://www.aacn.nche.edu/ media-relations/fact-sheets/nursing-faculty-shortage

[12] Cronenwett, L., Dracup, K., Grey, M., McCauley, L., Meleis, A., \& Salmon, M. The doctor of nursing practice: A national workforce perspective. Nursing Outlook. 2011; 59:9-17. http://dx.doi.org/10.1016/j.outlook.2010.11.003

[13] Loomis, J.A., Willard, B., \& Cohen, J. Difficult professional choices: deciding between the PhD and the DNP in nursing. OJIN: The Online Journals of Issues in Nursing. 2006; 12(1). http://dx.doi.org/10.3913/OJIN.Vol12No1PPT02

[14] McCreery, H. DNP or PhD: which is right for you? OSN Connect. 2011; 26(6): 8-12.

[15] Jolley, J. Choose your doctorate. Journal of Clinical Nursing. 2007; 16(2): 225-233. PMid:17239057 http://dx.doi.org/10.1111/j.1365-2702.2007.01582.x

[16] Minnick, A.F., Norman, L.D., Donaghey, B., Fisher, L.W., \& McKirgan, I.M. Defining and describing capacity issues in U.S. Doctor of Nursing Practice programs. Nursing Outlook. 2011; 58: 36-43. PMid:20113753

http://dx.doi.org/10.1016/j.outlook.2009.10.001

[17] Blenner, J.L. Development of the stimulus intensity modulation scale. Journal of Nursing Measurement. 1993; 1: 5-18. PMid:7828047

[18] Allen, L. The Nursing Shortage Continues As Faculty Shortage Grows. Nursing Economic\$. 2008; 26(1): 35-40. PMid:18389840

[19] Clark, C., Farnsworth, J., \& Landrum, R.E. Development and Description of the Incivility in Nursing Education (INE) Survey. Journal of Theory Construction \& Testing. 2009; 13(1): 7-15.

[20] Clark, C., \& Springer, P. THOUGHTS on INCVILITY: Student and Faculty Percpetions of UNCIVIL BEHAVIOR in Nursing Education. Nursing Education perspectives. 2007; 28(2): 93-97. 